\title{
Exercise for the management of type 2 diabetes: a review of the evidence
}

\author{
Silvano Zanuso $\cdot$ A. Jimenez $\cdot$ G. Pugliese $\cdot$ \\ G. Corigliano $\cdot$ S. Balducci
}

Received: 30 March 2009/Accepted: 8 April 2009/Published online: 3 June 2009

(C) Springer-Verlag 2009

\begin{abstract}
The aim is to critically review the more relevant evidence on the interrelationships between exercise and metabolic outcomes. The research questions addressed in the recent specific literature with the most relevant randomized controlled trials, meta-analysis and cohort studies are presented in three domains: aerobic exercise, resistance exercise, combined aerobic and resistance exercise. From this review appear that the effects of aerobic exercise are well established, and interventions with more vigorous aerobic exercise programs resulted in greater reductions in $\mathrm{HbA}_{1 \mathrm{c}}$, greater increase in $\mathrm{VO}_{2 \max }$ and greater increase in insulin sensitivity. Considering the available evidence, it appears that resistance training could be an effective intervention to help glycemic control, especially considering that the effects of this form of intervention are comparable with what reported with aerobic exercise. Less studies have investigated whether combined resistance and aerobic training
\end{abstract}

\section{S. Zanuso $(\bowtie)$}

Department of Exercise Science, Faculty of Medicine, University of Padua, Padua, Italy

e-mail: szanuso@gmail.com

\author{
A. Jimenez \\ Physical Activity and Sports Sciences Faculty, \\ European University of Madrid, Madrid, Spain \\ G. Pugliese \\ Diabetes Division, Department of Clinical Sciences, \\ S. Andrea Hospital, 2nd Medical School, \\ "La Sapienza" University, Rome, Italy \\ G. Corigliano \\ A.I.D. (Italian Diabetes Association) Outpatient Service, \\ Naples, Italy \\ S. Balducci \\ Metabolic Fitness Association, Monterotondo, Rome, Italy
}

offers a synergistic and incremental effect on glycemic control; however, from the available evidences appear that combined exercise training seems to determine additional change in $\mathrm{HbA}_{1 \mathrm{c}}$ that can be seen significant if compared with aerobic training alone and resistance training alone.

Keywords Exercise - Physical activity - Type-2 diabetes . Glycemic control

\section{Introduction}

For many years, physical activity has been-along with diet and medication - considered fundamental in the treatment of diabetes [1], and based on a number of large randomized controlled trials, physical activity and exercise have recently been recommended to prevent and treat diabetes according to ADA [2] ACSM [3, 4] and other national guidelines [5]. Moreover, considering the potential adverse effects attributed to some drugs [6,7], the clinical importance of physical activity, as well as that of therapeutic education [8] is even increasing. However, the terms "physical activity" and "exercise" denote two different concepts [9]. "Physical activity" refers to any bodily movement produced by skeletal muscles that results in an expenditure of energy (expressed in kilocalories) and includes a broad range of occupational, leisure and daily activities. "Exercise" refers to planned or structured physical activity. It involves repetitive bodily movements performed to improve or maintain one or more of the components of physical fitness: aerobic capacity (or endurance capacity), muscular strength, muscular endurance, flexibility and body composition. Thus, not only the role of physical activity, but in addition that of exercise has long been recognized in the treatment regimen of type 2 diabetes patient, which results in a variety of 
physiological and metabolic adaptations. A considerable amount of literature has been published recently to attempt to identify safe and effective exercise programs for this section of population. The most clinically relevant recent advances related to people with type 2 diabetes and the following recommendations were proposed in the last ADA statement [10]. Summarizing the evidence from these reports relating to exercise recommendations, it appears that the most important factor is to design a program for individuals that will provide the proper amount of exercise to attain maximal benefit at the lowest risk. The most relevant research questions addressed in the recent specific literature will be presented in the following sections.

\section{The effects of aerobic exercise}

In the past, there have been numerous minor studies on the effects of aerobic exercise on patients with type 2 diabetes and offering distinct findings. Exercise interventions were generally found to reduce glycosylated hemoglobin $\left(\mathrm{HbA}_{1 \mathrm{c}}\right)$ even though more recently the effects on other parameters, such as carnitine, were investigated [11]. Some meta-analysis has been particularly useful in summarizing and analyzing prior research. In a meta-analysis, reviewing exercise intervention of at least 8 weeks of supervised exercise in type 2 diabetic individuals [12], regular aerobic exercise was seen to have a statistically and clinically significant effect on $\mathrm{VO}_{2 \max }$, and as reflected in $\mathrm{HbA}_{1 \mathrm{c}}$ this kind of intervention improve glycemic control while having little effect on body weight, as shown in another meta-analysis on exercise interventions including 14 studies: 12 with aerobic exercise and 2 with resistance exercise as the form of intervention [13]. In a more recent meta-analysis [14] on seven studies using aerobic exercise as the form of intervention, the reduction in $\mathrm{HbA}_{1 \mathrm{c}}$ was confirmed in conjunction with a statistically significant reduction of about $5 \%$ for LDL-C, whereas no statistically significant improvements were found for TC, HDL-C, TC/HDL-C or TG. As seen from the aforementioned meta-analysis, we could say that the effects of aerobic exercise on $\mathrm{HbA}_{1 \mathrm{c}}$ (the major marker of glycemic control), are well established. However, the most interesting question to be addressed, it is not the effect of aerobic exercise itself but the effects of exercise intensity, specifically, vigorous exercise versus moderate physical activity (typically walking). The ideal study to address the benefits of low intensity versus vigorous aerobic exercise would be to randomize several thousand subjects with diabetes to either moderate or vigorous aerobic exercise and follow them for several years to determine effects on morbidity and mortality, but obviously such a study has yet to be undertaken and we subsequently are forced to resort to extrapolation from meta-regression analysis across trials in people affected by diabetes, randomized trials in non-diabetic subjects, cohort studies in people with diabetes. A more focused meta-analysis to address the issue of exercise intensity is that by Boulè et al. [12]: inclusion criteria required adults with type 2 diabetes (no IGT), only controlled clinical trials ( $>8$ weeks) evaluating aerobic exercise intervention with detailed prescription and supervised intervention. Seven studies were selected, with nine comparisons and a total of 266 subjects. The mean frequency was 3.4 sessions/week, with mean duration of 20 weeks, mean session duration of $49 \mathrm{~min}$ and the mean intensity of $55 \% \mathrm{VO}_{2 \max }$. The dependent variables were the difference in $\mathrm{HbA}_{1 \mathrm{c}}$ and $\mathrm{VO}_{2 \max }$ between exercise and control groups at the end of the study; the independent variables were exercise intensity $\left(\% \quad \mathrm{VO}_{2 \max }\right)$ and volume $\left(\mathrm{MET} \mathrm{h}^{-1}\right.$ week $\left.^{-1}\right)$. Exercise intensity was a better predictor than exercise volume of the difference in $\mathrm{HbA}_{1 \mathrm{c}}$ and $\mathrm{VO}_{2 \max }$ between the exercise and the control group. Of particular interest, among the studies included in this meta-analysis, Mourier et al. [15] reported that twenty-one subjects were enrolled (10 exercise and 11 controls) and the pre-training phase (averaging 2 weeks) required $3 \times /$ weeks sessions on cycle ergometer until training at $75 \%$ of $\mathrm{VO}_{2 \text { peak }}$ was attained. Subsequently, subjects trained 8 weeks at high intensity on a cycle ergometer combining training at $75 \%$ of $\mathrm{VO}_{2 \text { peak }}$ (continuous for $45 \mathrm{~min}$ ) and interval training (5 cycles for $2 \mathrm{~min}$ ) at $85 \%$ of $\mathrm{VO}_{2 \text { peak }}$ alternating with $3 \mathrm{~min}$ at $50 \%$ of $\mathrm{VO}_{2 \text { peak. An additional week of training was }}$ added if a day of training was missed (this occurred for two men). The results, based on the 10 completers showed a statistically significant elevated effect versus the sedentary control group on the following parameters: increase in $\mathrm{VO}_{2 \text { peak }}$, decrease of $\mathrm{HbA}_{1 \mathrm{c}} \%$, decrease of subcutaneous and visceral abdominal fat, increase of mid-tight muscle. The effect of exercise intensity was also recently evaluated on insulin sensitivity: three randomized controlled trials [16-18] and a review [19] compared the effects on insulin sensitivity of different intensities of aerobic exercise training with the same total energy expenditure on exercise. We can conclude by stating that interventions with more vigorous aerobic exercise programs resulted in greater reductions in $\mathrm{HbA}_{1 \mathrm{c}}$, greater increase in $\mathrm{VO}_{2 \max }$ and greater increase in insulin sensitivity.

\section{The effects of resistance exercise}

Resistance exercise has not benefited from as in-depth studies as aerobic exercise and only recently has been recognized as a useful therapeutic training procedure for the treatment of a number of chronic diseases, the reduction of multiple cardiovascular risk factors as well as the improvement of insulin action on tissue, leading favorably 
on prevention and treatment of type 2 diabetes. The early studies offering preliminary evidence for the benefits of resistance training with type 2 diabetic patients were published 10 years ago. Honkola et al. [20] reported how 5 months of progressive circuit resistance training did not result in a significant reduction in $\mathrm{HbA}_{1 \mathrm{c}}$, but the difference between the exercise and comparison groups pre to postintervention was significant, primarily due to a $0.4 \%$ rise in the non-exercising group. However, resistance training significantly lowered LDL cholesterol and reduced fasting triglycerides levels compared with the non-exercising control group. Eriksson et al. [21], demonstrated how three months of moderate-intensity circuit resistance training significantly decreased $\mathrm{HbA}_{1 \mathrm{c}}$, a reduction mainly due to improvements in lean body mass, as a strong inverse correlation between $\mathrm{HbA}_{1 \mathrm{c}}$ and muscle cross-sectional area post-training. The first RCT by Dunstan et al. [22] reported how moderate-intensity circuit resistance training reduced the plasma insulin response to glucose ingestion during an oral tolerance test, which finally led to improved selfmonitored blood glucose measurements. Ishii et al. [23] used a hyperinsulinemic-euglycemic clamp to verify that glucose disposal rate increased by $48 \%$ with high volume, moderate-intensity resistance training performed over 4-6 weeks compared with non-exercising control. Both Dunstan and Ishii reported a non-significant change in $\mathrm{HbA}_{1 \mathrm{c}}$ whose most likely explanation by the short duration of training (8 and 6 weeks, respectively) or the lack of intensity and/or volume, which may not have allowed the full effect of the intervention on $\mathrm{HbA}_{1 \mathrm{c}}$ to occur. Later, two extensive RCTs incorporated higher intensity resistance training and a longer duration was executed. Dunstan [24] randomized 36 overweight older men and women into a progressive resistance training plus moderate weight loss group or a moderate weight loss group, which did not execute any specific exercise training (only flexibility exercises). A greater reduction in $\mathrm{HbA}_{1 \mathrm{c}}$ was observed in the training group compared to weight loss alone in the absence of difference for waist circumference or total fat mass between groups. Similar findings were reported by Castaneda [25], who randomized 62 older adults into either supervised high-intensity progressive resistance training or a non-exercising control group. In the resistance training group muscle glycogen storage increased by $31 \%$ and $\mathrm{HbA}_{1 \mathrm{c}}$ was reduced from 8.7 to $7.6 \%$; systolic blood pressure was also reduced, with a mean increase in lean tissue mass of $1.2 \mathrm{~kg}$. There were no differences in other cardiovascular risk factors such HDL, LDL and total cholesterol levels. The control group exhibited no change in $\mathrm{HbA}_{1 \mathrm{c}}$ and a $23 \%$ reduction in muscle glycogen storage. Another important finding of the Castaneda study was that medication for diabetes was reduced by $72 \%$ for individuals in the resistance-trained group when compared with
$3 \%$ in the control group. Slightly more moderate-intensity resistance exercise programs were utilized by Baldi et al. [26] in another RCT. They reported a significant reduction in $\mathrm{HbA}_{1 \mathrm{c}}$, fasting glucose and insulin and a significant increase in fat-free mass. Dunstan [24], Castaneda [25] and Baldi [26] agree that increases in skeletal muscle mass are related to decreases in $\mathrm{HbA}_{1 \mathrm{c}}$ and support the hypothesis that resistance training improves glycemic control by increasing the skeletal muscle storage of glucose. It is still not clear, however, if this effect is due to an increase in muscle size and/or qualitative changes of certain muscular functions. The conclusion that increased muscle mass could clear an increased amount of blood glucose, was reported by Miller et al. [27] evaluating the effects of resistance training in young males after a 10 -week resistance program. He observed, that in post-training as opposed to pre-training, that during an oral glucose tolerance test reduced levels of insulin were required to achieve the same effect on plasma glucose concentration with the glucose response unaltered, suggesting an improvement in insulin sensitivity. This increased insulin sensitivity was correlated with increased lean body mass, leading to the conclusion that the effects of resistance training on insulin sensitivity were attributable to an increase in muscle mass. Later, however, others argued for changes in quality of the muscle, as opposed solely to quantity, as important for improving skeletal muscle insulin sensitivity [28]. Also Ishii et al. [23] reported that insulin sensitivity occurred in the absence of an alteration in lean body mass, with data conveyed relative to the fat-free mass, as an attempt to compensate for the effect of a larger muscle mass in resistance-trained individuals, suggesting that qualitative improvements in skeletal muscle function play a role in the resistance training induced improvements in insulin sensitivity. Two more recent interesting studies helped to address this issue. One was conducted on humans [29], the other on rats [30]. The results of Holten et al. [29] contradict previous research arguing that improved insulin signaling is determined by increased muscle mass rather than quality in response to a strength-training period. They strength-trained an individual leg of healthy subjects and patients with type 2 diabetes. After strength-training, muscle biopsies were obtained, and an isoglycemichyperinsulinemic clamp and arteriofemoral venous catheterization of both legs performed. They found that strength-training of a single leg increases insulin-mediated glucose clearance in both groups and the adaptation was considered attributable to local contraction-mediated mechanisms involving key proteins in the insulin signaling cascade. This effect was independent of an increase in muscle mass. Thus, skeletal muscle also adapts qualitatively to a strength-training program. Moreover, the study has revealed possible mechanisms behind the effect of 
training (i.e., changes in protein contents of GLUT4, PKB and GS). Finally, they have shown that the adaptations occurred in response to a minimal training effort, which could easily be carried out on a larger scale. Ibanez et al. [31] demonstrated that resistance exercise reduces visceral and subcutaneous fat with an increase in insulin sensitivity. Since abdominal adiposity has also been linked to insulin resistance, this could be another mechanism to explain the positive effects of resistance training on insulin resistance and even though the small sample size and uncontrolled study design mean that care should be taken in interpreting these findings it would appear that reductions in visceral and subcutaneous adiposity with resistance training might not be the mechanism responsible for the improved insulin sensitivity with this type of training [32]. In the light of the available evidence, it appears that resistance training could be an effective intervention to assist glycemic control, especially since, according to the three major RCTs [24-26] the effects of this form of intervention are comparable of aerobic exercise as reported in Boulè et al. [12] meta-analysis. Moreover, there exists some controversy over whether the exercise-induced benefits of glucose and insulin control are a result of multiple single bouts of exercise or whether there is a chronic training benefit.

\section{Combined aerobic and resistance exercise}

Whether combined resistance and aerobic training offers a synergistic and incremental effect on glycemic control in individuals with type 2 diabetes is an issue that has been addressed by a number of studies [33-35]. Moreover, if there is an incremental value to combined aerobic and resistance training - as opposed to separately - is another interesting research question that has been addressed in the studies by Cuff et al. [36] and more recently by Sigal et al. [37]. Maiorana [33] investigated the effects of an 8-week long circuit training program, combining aerobic and resistance exercise, compared with a non-training period. Subjects were randomly allocated a group. Muscular strength increased with training while skin folds, the percentage of body fat and waist:hip ratio significantly decreased. Concurrently, following training, peak oxygen uptake and exercise test duration increased, with a decrease in $\mathrm{HbA}_{1 \mathrm{c}}$ and fasting blood glucose. Balducci et al. [34] demonstrated that even low- to moderate-intensity resistance training, combined with moderate aerobic exercise three times a week for a year significantly improved metabolic and lipidic profiles, adiposity and blood pressure. More specifically, compared with a non-exercising comparison group, $\mathrm{HbA}_{1 \mathrm{c}}$ and fat mass was significantly reduced while fat-free mass increased. Additionally, fasting blood glucose, LDL cholesterol and total cholesterol were significantly reduced while HDL cholesterol was increased. The findings of this study demonstrate a global improvement in cardiovascular risk factors with a marked improvement in $\mathrm{HbA}_{1 \mathrm{c}}$ and highlight the potential benefits of combined training for individuals with type 2 diabetes. Furthermore these findings also identify that longer duration, more moderate resistance training may be as efficient as short-term high-intensity programs at maintaining glucose homeostasis and reducing cardiovascular risk factors. However, as stated in a recent review by Eves and Plotnikoff [32], some caution is required in the interpretation of these results, as study participants were allowed to select an exercise or non-exercise group and Balducci et al. [34] did not report the post-intervention change between groups. The purpose of the study published by Tokmakidis et al. [35] was to investigate the short-term (1 month) and long-term (4 month) effects of a combined program consisting of two aerobic and two training sessions a week in a group of nine postmenopausal women. Significant reductions were observed in both the glucose and insulin areas under the curve after 4 weeks of training. These adaptations were further improved after 16 weeks. $\mathrm{HbA}_{1 \mathrm{c}}$ was significantly decreased after 4 weeks and after 16 weeks of exercise training. In addition, cardiovascular endurance and muscular strength were significantly improved after 4 and 16 weeks of training. Body mass and body mass index, however, were not significantly altered throughout the study. The results indicate that a combined training program of strength and aerobic exercises could induce positive adaptations on glucose control, insulin action, muscular strength and exercise tolerance in women with type 2 diabetes. Cuff et al. [36] were the first to compare combined aerobic and resistance training with an aerobiconly training group as well as a non-exercising control group. While both training regimes (combined and aerobiconly) resulted in significant reductions in body weight and abdominal adiposity, only the combined group revealed improved insulin sensitivity, glucose disposal and a markedly greater increase in muscle density. Improved glucose disposal with training was significantly related to the reductions in abdominal subcutaneous and visceral adipose tissue. These findings are at variance with the above-mentioned study of Ibanez et al. [31] and would suggest that improved glucose clearance was a result of both reduced visceral adiposity as well as enhanced muscle quality. Although this study [36] showed a lack of variations in $\mathrm{HbA}_{1 \mathrm{c}}$ values between the groups, the low average baseline $\mathrm{HbA}_{1 \mathrm{c}}(6.7 \%)$ and small sample (9-10 persons per group) limited the capacity to detect a difference. The most recent study (and the only one with this study design) aimed to evaluate whether combined resistance and aerobic training offers an incremental value versus either alone and versus a sedentary control group is the DARE (Diabetes 
Aerobic and Resistance Exercise) by Sigal et al. [37]. The primary outcome was a change in $\mathrm{HbA}_{1 \mathrm{c}}$ from baseline to termination of the intervention and the secondary outcomes of plasma lipid levels, blood pressure and body composition. The hypothesis of the study was that the decrease in $\mathrm{HbA}_{1 \mathrm{c}}$ would be greater in the aerobic and resistance training groups than the control group and would be even greater in the combined exercise training group than the aerobic or resistance training group. The absolute change in $\mathrm{HbA}_{1 \mathrm{c}}$ was significantly higher in both the aerobic and the resistance training group compared with the control group. Combined exercise training resulted in an additional change in $\mathrm{HbA}_{1 \mathrm{c}}$ that achieved statistical significance if compared with aerobic training alone and with resistance training alone. Changes in blood pressure and lipid values did not significantly differ statistically among groups; adverse events were more common in the exercise groups (Tables 1, 2).

\section{Summary and conclusions}

In recent years, clinical trials and cohort studies have highlighted the role of physical activity in the prevention of type 2 diabetes. Most of the studies have focused on people with impaired glucose tolerance because they are high risk of developing type 2 diabetes. Interventions have been diverse and can generally be defined as 'lifestyle interventions' with the mechanisms under investigation consisting of diet, physical activity, exercise, separately or in combination. The prime objective of diabetes therapy-the reduction of body fat and hyperglycemia - was shown to be potentially reversible following appropriate lifestyle intervention that incorporates physical activity. The most significant randomized clinical trials published in the literature evaluated the effect of dietary and physical activity interventions in populations at high risk for developing diabetes. However, not only the role of physical

Table 1 Summary of the most significant studies

\begin{tabular}{|c|c|c|c|c|c|}
\hline Author & Subjects & $W$ & $S$ & T.M. & Program \\
\hline Eriksson et al. [21] & 8 & 12 & 3 & CWT & 1 set of $15-20$ reps; $30 \mathrm{~s}$ between exercises \\
\hline Honkola et al. [20] & $38(18 \mathrm{E}+20 \mathrm{C})$ & 20 & 2 & CWT & $\begin{array}{l}8-10 \text { ex; } 2 \text { sets of } 12-15 \text { reps; } 30 \text { s light cycling } \\
\text { between exercises }\end{array}$ \\
\hline Dunstan et al. [22] & $27(15 \mathrm{E}+12 \mathrm{C})$ & 8 & 3 & CWT & $2 / 3$ Sets of $10-15$ reps \\
\hline Ishii et al. [23] & $17(9 \mathrm{E}+8 \mathrm{C})$ & $4-6$ & 5 & RT & $\begin{array}{l}9 \text { Ex. } 40-50 \% 1 \mathrm{RM} \text {; upper body } 2 \times 10 \text {, lower body } \\
2 \times 20\end{array}$ \\
\hline Maiorana et al. [33] & 16 & 8 & 3 & $\mathrm{CT}$ & $\begin{array}{l}\text { 7-8 Res. Exe }+7 \text { cycling stations, RT } 55-65 \% \\
\text { 1RM, AT } 85 \% \text { Max HR }\end{array}$ \\
\hline Dunstan et al. [24] & $36(19 \mathrm{E}+17 \mathrm{C})$ & 26 & 3 & PRT & $\begin{array}{l}9 \text { Ex. Weeks } 1-2,50-60 \% \text { 1RM; Weeks 3-26, } \\
\text { 75-80\% 1RM, 8-10 reps }\end{array}$ \\
\hline Castaneda et al. [25] & $62(31 \mathrm{E}+31 \mathrm{C})$ & 16 & 3 & PRT & $\begin{array}{l}5 \text { Ex. Weeks } 1-8,60-80 \% \text { 1RM; Weeks } 10-14 \text {, } \\
70-80 \% \text {; Week } 9 \text { and } 15 \text { decrease of } 10 \%\end{array}$ \\
\hline Baldi et al. [26] & $18(9 \mathrm{E}+9 \mathrm{C})$ & 10 & 3 & PRT & $\begin{array}{l}10 \text { Ex. } 10 \text { RM, upper body } 15 \text { RM, lower body, } \\
\text { intensity progression of } 5 \%\end{array}$ \\
\hline $\begin{array}{l}\text { Fennicchia et al. } \\
\text { (2004) }\end{array}$ & $14(7 \mathrm{E}+7 \mathrm{C})$ & 6 & 3 & RT & 8 Ex. Intensity $8-12$ RM $3 \times 8-12$ \\
\hline Ibanez et al. [31] & 9 & 16 & 2 & PRT & $\begin{array}{l}\text { 7-8 Ex. Weeks } 1-8,50-70 \% 1 \text { RM } 3 \times 10-15 ; \\
\text { Weeks } 9-16,70-80 \% 1 \text { RM 3-5 × 80\% 1RM }\end{array}$ \\
\hline Cuff et al. [36] & $28(9 \mathrm{C}+10 \mathrm{E}+9 \mathrm{E})$ & 16 & 3 & $\mathrm{RT}+\mathrm{AT}$ vs. AT & $\begin{array}{l}5 \text { Ex. RT intensity not reported, } 2 \times 12 \text { AT many } \\
\text { different modes at } 65 \% \text { HRR }\end{array}$ \\
\hline Tokmakidis et al. [35] & 9 & 16 & 2 & $\mathrm{RT}+\mathrm{AT}$ & $\begin{array}{l}\text { RT } 6 \text { Ex. } 60 \% 1 \text { RM } 3 \times 10-15 \text {; AT walking } \\
\text { jogging at } 65-75 \% \text { MHR }\end{array}$ \\
\hline Balducci et al. [34] & $120(60 \mathrm{E}+60 \mathrm{C})$ & 56 & 3 & $\mathrm{RT}+\mathrm{AT}$ & 6 Ex. RT $40-60 \% 1$ RM $3 \times 12$; AT $40-80 \%$ HRR \\
\hline O'Donovan et al. [16] & $36(13 \mathrm{C}+10 \mathrm{E}+13 \mathrm{E})$ & 24 & 3 & AT (HI vs. LI) & Cycle ergometer at 60 or $80 \%$ of $\mathrm{VO}_{2 \max }$ \\
\hline Coker et al. [17] & 21 & 12 & 4 & AT (HI vs. LI) & Cycle ergometer at 50 or $75 \%$ of $\mathrm{VO}_{2 \max }$ \\
\hline Di Pietro et al. [18] & 25 & 36 & 4 & AT (HI vs. LI) & $\begin{array}{l}\text { Treadmill; mini trampoline; rowing ergometer at } \\
65 \% \text { or } 80 \% \text { of } \mathrm{VO}_{2 \max }\end{array}$ \\
\hline Sigal et al. [37] & $\begin{array}{l}251 \\
(64 \mathrm{C}+60 \mathrm{E}+64 \mathrm{E}+63 \mathrm{E})\end{array}$ & 22 & 3 & $\begin{array}{l}\text { AT vs. RT vs. } \\
\text { AT }+ \text { RT }\end{array}$ & $\begin{array}{l}\text { AT (treadmill or bicycle) at } 60-75 \% \text { of MHR. RT } \\
\text { (7 strength machines- } 2 / 3 \text { sets at } 80 \% 1 \mathrm{RM})\end{array}$ \\
\hline
\end{tabular}

$W$ weeks of training, $S$ session per week, $T M$ training modality, $C W T$ circuit weight training, $P R T$ progressive resistance training, $R T$ resistance training, $A T$ aerobic training, $H I$ high intensity, $L I$ low intensity, Ex. exercise, $H R R$ heart rate reserve, MHR maximal heart rate 
Table 2 Summary of the most significant study's results

\begin{tabular}{|c|c|}
\hline Author & Main results \\
\hline Eriksson et al. [21] & CWT determined a decrease in $\mathrm{HbA}_{1 \mathrm{c}}$; no change in fasting plasma glucose \\
\hline Honkola et al. [20] & Exercise group improved in $\mathrm{HbA}_{1 \mathrm{c}}$; total cholesterol, LDL and triglycerides \\
\hline Dunstan et al. [22] & Significant reduction of both the glucose and insulin area under the curve at 2-h OGTT \\
\hline Ishii et al. [23] & $\begin{array}{l}\text { Increase of glucose disposal rate during hyperinsulinemic-euglycemic clamp. Increase in quadriceps } \\
\text { strength. No changes in body composition }\end{array}$ \\
\hline Maiorana et al. (2002) & $\begin{array}{l}\text { Increase of muscular strength and peak oxygen uptake. Decrease of skinfolds, } \% \text { of body fat, waist-to-hip } \\
\text { ratio, } \mathrm{HbA}_{1 \mathrm{c}} \text { and fasting glucose }\end{array}$ \\
\hline Dunstan et al. [24] & $\begin{array}{l}\text { Decrease in } \mathrm{HbA}_{1 \mathrm{c}} \text { body weight and fat mass. Increase in lean body mass. No changes in fasting glucose, } \\
\text { insulin, serum lipoproteins and resting } \mathrm{BP}\end{array}$ \\
\hline Castaneda et al. [25] & Decrease in $\mathrm{HbA}_{1 \mathrm{c}}$ and in prescribed diabetes medications. Increase in muscle glycogen stores \\
\hline Baldi et al. [26] & Ten weeks of PRT determined a decreased in fasting blood glucose and $\mathrm{HbA}_{1 \mathrm{c}}$. No changes at the OGTT \\
\hline Fennicchia et al. (2004) & $\begin{array}{l}\text { Increase of muscular strength and integrated glucose concentration after the acute bout of exercise. No } \\
\text { changes in insulin concentration after any exercise bout }\end{array}$ \\
\hline Ibanez et al. [31] & $\begin{array}{l}\text { PRT determined increase of legs and arm strength and increase of insulin sensitivity. Fasting blood } \\
\text { glucose, visceral and subcutaneous fat decreased }\end{array}$ \\
\hline Cuff et al. [36] & $\begin{array}{l}\text { Combined }(\mathrm{AT}+\mathrm{RT}) \text { training determined greater increase in glucose infusion rate and muscle density } \\
\text { than AT only group. Both groups decreased subcutaneous and visceral fat }\end{array}$ \\
\hline Tokmakidis et al. [35] & $\begin{array}{l}\text { At 2-h OGTT: reductions of glucose and insulin areas under the curve. Improvement of muscular strength } \\
\text { and aerobic capacity. No changes of body mass index }\end{array}$ \\
\hline Balducci et al. [34] & $\begin{array}{l}12 \text { months of low intensity combined aerobic }+ \text { resistance exercise determined a decreased in fasting } \\
\text { blood glucose and } \mathrm{HbA}_{1 \mathrm{c}}\end{array}$ \\
\hline O’Donovan [16] & $\begin{array}{l}\text { Moderate-intensity exercise is as effective as high-intensity exercise when } 400 \mathrm{kcal} \text { are expended per } \\
\text { session in: insulin sensitivity score and insulin concentration }\end{array}$ \\
\hline Coker et. al. [17] & $\begin{array}{l}\text { Insulin stimulated glucose disposal did not changed with moderate-intensity exercise training while it } \\
\text { increased by } 20 \% \text { with high-intensity exercise }\end{array}$ \\
\hline Di Pietro [18] & $\begin{array}{l}\text { Long-term higher intensity exercise provide more enduring benefits on insulin action compared with } \\
\text { moderate or low intensity exercise }\end{array}$ \\
\hline Sigal et al. [37] & $\begin{array}{l}\text { Either aerobic or resistance training alone improve glycemic control in type } 2 \text { diabetes, but the } \\
\text { improvements are greater with combined aerobic and resistance training }\end{array}$ \\
\hline
\end{tabular}

activity but also that of exercise has long been recognized in the treatment regimen of type 2 diabetes patients, which results in a variety of physiological and metabolic adaptations in both non-diabetic and diabetic subjects. As a result, a considerable amount of literature has been published in recent years trying to identify safe and effective exercise programs for this section of population. The benefits of aerobic exercise are well documented and their effects in patients with type 2 diabetes are widely perceived to be beneficial for glycemic control, weight loss, and the control of lipids and lipoproteins. Some recent meta-analysis has been particularly useful in summarizing and analyzing prior research and the effects of aerobic exercise on $\mathrm{HbA}_{1 \mathrm{c}}$, the major marker of glycemic control have become well established. However, the most interesting question to be addressed today, it is not the effect of aerobic exercise itself but the effect of exercise intensity.

Well-conducted meta-analysis has shown that intensity is a better predictor than exercise volume of both the difference in $\mathrm{HbA}_{1 \mathrm{c}}$ and $\mathrm{VO}_{2 \max }$ between the exercise and the control group. The effect of exercise intensity was also recently evaluated on insulin sensitivity by means of randomized controlled trials that compared the effects on insulin sensitivity of different intensities of aerobic exercise training with the same total energy expenditure on exercise. In conclusion, we can say that interventions with more vigorous aerobic exercise programs resulted in greater reductions in $\mathrm{HbA}_{1 \mathrm{c}}$, greater increase in $\mathrm{VO}_{2 \max }$ and greater increase in insulin sensitivity.

Also resistance training has been shown to be beneficial with type 2 diabetic patients in a number of studies. Considering the available evidence, it appears that resistance training could be an effective intervention to help glycemic control, especially considering that the effects of this form of intervention as reported in the three major RCTs is comparable with what reported with aerobic exercise. Whether combined resistance and aerobic training offers a synergistic and incremental effect on glycemic control in individuals with type 2 diabetes is an issue that has been addressed by a number of studies; in general, the results indicated that a combined training program of strength and aerobic could induce positive adaptations on glucose 
control, insulin action, muscular strength and exercise tolerance. Moreover, if there is an incremental value to combined aerobic and resistance training as opposed to either separately is another interesting research question that has been addressed in research recently. Combined exercise training seems to determine additional change in $\mathrm{HbA}_{1 \mathrm{c}}$ that can be seen significant if compared with aerobic training alone and resistance training alone.

However, from this review, it is clear that no known studies have been conducted to address the efficacy of combined resistance and aerobic training program over the long term on a large group of patients with type 2 diabetes, since the longest study duration was 6 months. Moreover, no research has yet been undertaken on the efficacy of a mixed exercise interventions versus a control group that was neither a non-exercise group nor an exercise group training with aerobic or strength exercises.

Moreover, no studies have evaluated the effect of different exercise intensities on $\mathrm{HbA}_{1 \mathrm{c}}$, some selected physiological parameters $\left(\mathrm{VO}_{2 \max }\right.$, maximal strength, flexibility) as well as on cardiovascular risk factors.

\section{References}

1. Joslin EP, Root EF, White P (1959) The treatment of diabetes mellitus. Lea \& Febiger, Philadelphia

2. Sigal RJ, Wasserman DH, Kenny GP, Castaneda C (2004) Physical activity/exercise and type 2 diabetes. Diabetes Care 10:2518-2539

3. ADA/ACSM (1997) Joint statement: diabetes mellitus and exercise. Med Sci Sport Exercise 29(12):i-vi

4. American College of Sports Medicine (2000) Position stand: exercise and type 2 diabetes. Med Sci Sports Exerc 22:13451360

5. De Micheli A (2008) Italian standards for diabetes mellitus 2007 : executive summary. Acta Diabetol 45:107-127

6. Nissen SE, Wolski K (2007) Effect of rosiglitazone on the risk of myocardial infarction and death from cardiovascular causes. $\mathrm{N}$ Engl J Med 356(24):2457-2471

7. Pantalone KM, Kattan MW, Yu C, Wells BJ, Arrigain S, Jain A, Atreja A, Zimmerman RS (2009) The risk of developing coronary artery disease or congestive heart failure, and overall mortality, in type 2 diabetic patients receiving rosiglitazone, pioglitazone, metformin, or sulfonylureas: a retrospective analysis. Acta Diabetol [Epub ahead of print]

8. Albano MG, Crozet C, d'Ivernois JF (2008) Analysis of the 2004-2007 literature on therapeutic patient education in diabetes: results and trends. Acta diabetol 45:211-219

9. U.S. Department of Health and Human Services (1996) Physical activity and health: a report of the Surgeon General. U.S. Department of Health and Human Services, Centers for Disease Control and Prevention, National Center for Chronic disease Prevention and Health Promotion, Atlanta

10. Sigal RJ, Castaneda C, Kenny GP, White RD, Wasserman D (2006) Physical activity/exercise and type 2 diabetes. Diabetes Care 6:1433-1438

11. Ferland A, Broderick TL, Nadeau A, Simard S, Martin J, Poirier $P$ (2007) Impact of fasting and postprandial state on plasma carnitine concentrations during aerobic exercise in type 2 diabetes. Acta Diabetol 44(3):114-120

12. Boulè NG, Haddad E, Kenny GP, Wells GA, Sigal RJ (2001) Effects of exercise on glycemic control and body mass in type 2 diabetes mellitus: a meta-analysis of controlled clinical trials. JAMA 286:1218-1227

13. Boulè NG, Kenny GP, Hadda E, Wells GA, Sigal RJ (2003) Meta-analysis of the effect of structured exercise training on cardiorespiratory fitness in Type 2 diabetes mellitus. Diabetologia 46:1071-1081

14. Kelley GA, Kelley KS (2007) Effects of aerobic exercise on lipids and lipoproteins in adults with type 2 diabetes a metaanalysis of randomized-controlled trials. Public Health 121(9):643-655

15. Mourier A, Gautier JF, De Kerviler E (1997) Mobilization of visceral adipose tissue related to the improvement in insulin sensitivity in response to physical training in NIDDM. Effects of branched-chain amino acid supplements. Diabetes Care 20:385391

16. O'Donovan G, Kearney EM, Nevill AM, Woolf-May K, Bird SR (2005) The effects of 24 weeks of moderate- or high-intensity exercise on insulin resistance. Eur J Appl Physiol 95(5-6):522528

17. Coker R, Hays NP, Williams RH, Brown AD, Freeling SA, Kortebein PM, Sullivan DH, Starling RD, Williams JE (2006) Exercise-induced changes in insulin action and glycogen metabolism in elderly adults. Med Sci Sport Exerc 38:433-438

18. Dipietro L, Dziura L, Yeckel CW, Darrel Neufer P (2006) Exercise and improved insulin sensitivity in older women: evidence of the enduring benefits of higher intensity training. J Appl Physiol 100:142-149

19. Gill JMR (2007) Physical activity, cardiorespiratory fitness and insulin resistance: a short update. Curr Opin Lipidol 18:47-52

20. Honkola A, Forsen T, Eriksson J (1997) Resistance training improves the metabolic profile in individuals with type 2 diabetes. Acta Diabetol 34:245-248

21. Eriksson J, Taimela S, Eriksson K, Parviainen S, Peltonen J, Kujala U (1997) Resistance training in treatment of non-insulindependent diabetes mellitus. Int J Sports Med 18:242-246

22. Dunstan DW, Puddey IB, Beilin LJ, Burke V, Morton AR, Stanton KG (1998) Effects of a short-term circuit weight training program on glycaemic control in NIDDM. Diabetes Res Clin Pract 40:53-61

23. Ishii T, Yamakita T, Sato T, Tanaka S, Fujii S (1998) Resistance training improves insulin sensitivity in NIDDM subjects without altering maximal oxygen uptake. Diabetes Care 21:1353-1355

24. Dunstan DW, Daly RM, Owen N, Jolley D, De Courten M, Shaw J, Zimmet P (2002) High-intensity resistance training improves glycemic control in older patients with type 2 diabetes. Diabetes Care 25:729-1736

25. Castaneda C, Layne JE, Munoz-Orians L, Gordon PL, Walsmith J, Foldvari M, Roubenoff R, Tucker KL, Nelson ME (2002) A randomized controlled trial of resistance exercise training to improve glycemic control in older adults with type 2 diabetes. Diabetes Care 25:2335-2341

26. Baldi JC, Snowling N (2003) Resistance training improves glycaemic control in obese type 2 diabetic man. Int J Sports Med 24:419-423

27. Miller WJ, Sherman WM, Ivy JL (1984) Effect of strength training on glucose tolerance and post-glucose insulin response. Med Sci Sports Exerc 16:539-543

28. Miller JP, Pratley RE, Goldberg AP et al (1994) Strength training increases insulin action in healthy $50-65$ year old men. J Appl Physiol 77:1122-1127

29. Holten MK, Zacho M, Gaster M, Jueal C, Wojtaszewsky JF, Dela F (2004) Strength training increases insulin-mediated glucose 
uptake, GLUT4 content, and insulin signalling in skeletal muscle in patients with type 2 diabetes. Diabetes 53:294-305

30. Yaspelkis BB (2006) Resistance training improves insulin signaling and action in skeletal muscle. Exerc Sport Sci Rev 34(1):42-46

31. Ibanez J, Izquierdo M, Arguelles I, Forga L, Larrion JL, GarciaUnciti M, Idoate F, Gorostiaga EM (2005) Twice weekly progressive resistance training decreases abdominal fat and improves insulin sensitivity in older man with type 2 diabetes. Diabetes Care 28:662-667

32. Eves NE, Plotnikoff RC (2006) Resistance training and type 2 diabetes. Diabetes Care 29:1933-1941

33. Maiorana A, O'Driscoll G, Cheetham C, Dembo L, Stanton K, Goodman C, Taylor R, Green D (2001) The effect of combined aerobic and resistance exercise on vascular function in type 2 diabetes. J Am Coll Cardiol 38:860-866
34. Balducci S, Leonetti F, Di Mario U, Fallucca F (2004) Is a longterm aerobic plus resistance training program feasible for and effective on metabolic profiles in type 2 diabetic patients? Diabetes Care 27:841-842

35. Tokmakidis SP, Zois CE, Volaklis KA, Kotsa K, Touvra AM (2004) The effects of a combined strength and aerobic exercise program on glucose control and insulin action in women with type 2 diabetes. Eur J Appl Physiol 92:437-442

36. Cuff DJ, Meneilly GS, Martin A, Ignaszewsky A, Tildesley HD, Frolich JJ (2003) Effective exercise modality to reduce insulin resistance in women with type 2 diabetes. Diabetes Care 26:2977-2982

37. Sigal RJ, Kenny GP, Boule' NG, Wells GA, Prud'homme D, Fortier M, Reid RD, Tulloch H, Coyle H, Phillips P, Jennings A, Jaffey J (2007) Effects of aerobic training, resistance training, or both on glycemic control in Type 2 diabetes. Ann Intern Med 147:357-369 